\title{
Hubungan Pemahaman Diri Terhadap Rasa Tanggung Jawab: Sebuah Survey Pada Anak Usia Dini di Kota Surabaya
}

\author{
Virginia Wulan Kurniasih"1, Fifi Khoirul Fitriyah², Muhammad Thamrin \\ Hidayat $^{3}$, Sunanto ${ }^{4}$ \\ 1,2,3,4 Universitas Nahdlatul Ulama Surabaya \\ Surabaya, Indonesia \\ Email: 4230016001@student.unusa.ac.id ${ }^{1}$, fifi@unusa.ac.id², pmksthamrin@gmail.com³ \\ alif30@unusa.ac.id ${ }^{4}$
}

\section{Kata kunci:}

Pemahaman Diri, Tanggung Jawab, Anak Usia Dini

\begin{abstract}
Abstrak
Sosial emosional merupakan salah satu aspek perkembangan anak usia dini yang penting mendapat perhatian, termasuk pada permasalahan pemahaman diri dan tanggung jawab. Meskipun sudah banyak penelitian yang mengkaji kaitan antara dua variabel tersebut, namun kajian untuk subjek anak usia dini masih terbatas. Tujuan penelitian ini adalah untuk menguji hubungan antara pemahaman diri dan tanggung jawab pada anak usia dini. Penelitian ini merupakan survey di Kecamatan Tenggilis, Kota Surabaya, yang melibatkan 134 anak usia dini. Alat pengumpul data menggunakan angket. Hasil penelitian menunjukkan terdapat hubungan yang signifikan antara pemahaman diri dan rasa tanggung jawab anak usia dini. Kontribusi penelitian ini adalah sebagai asesmen awal dalam pembelajaran anak usia dini khususnya pada pengembangan aspek sosial emosional.
\end{abstract}

\section{Keywords:}

Self

Understanding,

Responsibility,

Early Childhood

\begin{abstract}
Social emotional is one aspect of early childhood development that is important to get attention, including the problems of self-understanding and responsibility. Although there have been many studies examining the relationship between these two variables, studies for the subject of early childhood are still limited. The purpose of this study was to examine the relationship between self-understanding and responsibility in early childhood. This research is a survey in Tenggilis District, Surabaya City, which involved 134 early childhood children. The data collection tool uses a questionnaire. The results showed that there was a significant relationship between self-understanding and feelings of responsibility in early childhood. The contribution of this research is as an initial assessment in early childhood learning, especially in the development of the social emotional aspects.
\end{abstract}




\section{Pendahuluan}

Karakter tanggung jawab sangat penting dibentuk sejak usia dini, sebab karakter tanggung jawab ini sangat bermanfaat pada kehidupan masa depan anak dalam membentuk rasa tanggung jawab anak usia dini. Kita perlu membentuk konsep pemahaman diri anak terlebih dahulu dengan mengajarkan dasar-dasar nilai karakter, seperti memberikan peraturan disetiap kegiatannya agar anak terbiasa dengan hal itu, sebab pengembangan karakter anak tidak sekejap muncul. Karakter perlu dibentuk dan dikembangkan sejak anak usia dini untuk meningkatkan tanggung jawab anak, yaitu dengan cara memberikan tugas dan memberikan kepercayaan pada anak bahwa anak bisa melakukannya. Selain itu, anak dapat menghargai waktu, contohnya setelah bermain anak dapat membereskan dan merapihkan mainannya, dapat mengerjakan tugas sampai tuntas, anak dapat mengatakan hal-hal yang jujur dan mampu bergaul dengan teman-temannya. Semua proses itu akan membentuk kepribadian seorang anak dengan seiring berjalannya waktu, maka sangat penting menanamkan nilai-nilai pendidikan karakter untuk mempersiapkan mereka sebagai manusia yang mempunyai identitas diri, sekaligus menuntun anak untuk menjadi manusia berbudi pekerti melalui pembiasaan dan keteladanan. Anak usia dini cenderung memiliki sifat meniru apa yang dilakukan oleh orang-orang yang ada disekitarnya.

Menurut David P. Phillips (penggagas teori imitasi dan sugesti) menyimpulkan bahwa imitasi individu terjadi karena efek-efek media massa terhadap anggota masyarakat, sehingga kemudian dia menciptakan istilah cultural contagion (penularan kultural/budaya). Selain itu, meniru juga dihubungkan dengan teori belajar sosial dari Albert Bandura dalam teorinya, Bandura menekankan dua hal penting yang sangat mempengaruhi perilaku manusia, yaitu belajar secara observasional atau modelling yang lebih dikenal dengan teori pembelajaran sosial dan regulasi diri. Modelling dalam teori Bandura itulah yang dimaksud dengan meniru, di mana aktivitas tersebut harus melalui tahap perhatian, pengingatan dan reproduksi motoris yang mendapat dukungan motivasional dari dalam dan luar diri individu, sehingga menuntut orang tua dalam mengajarkan dan mengenalkan nilai-nilai karakter ataupun keteladanan anak sejak usia dini. Kebiasaan dan keteladanan inilah yang kemudian akan menjadi suatu karakter yang membekas dan tertanam dalam jiwa sang anak (Cahyaningrum, 2017).

Ada dua karakteristik dalam konsep diri, yaitu konsep diri positif dan konsep diri negatif. Konsep diri positif timbul dari keyakinan dan pola pikir yang positif terhadap kemampuan dan potensi yang dimiliki oleh individu tersebut, contohnya senang tampil di depan umum karena anak percaya dengan kemampuannya sendiri, dapat menghargai karya orang lain tidak mengejek karya temannya, dapat menyelesaikan tugasnya sendiri sampai tuntas dan mampu bermain sportif dengan teman-temannya. Sedangkan anak yang memiliki kontrol diri rendah agresivitasnya tinggi, percaya diri rendah, enggan untuk mencoba suatu hal yang baru, merasa tidak dicintai dan tidak diinginkan kecenderungan melempar kesalahan pada orang lain, contohnya mudah mengeluh, selalu mengejek dan membuat keributan dengan temannya, mudah menyerah dalam mengerjakan tugasnya dan selalu bergantung pada orang lain (Thahir dan Firdaus, 2017; Praptiani, 2013; Syam dan Amri, 2017; Adywibowo, 2010; Mukhtar et al, 2016; Keshky \& Samak, 2017; Mann et al, 2004).

Pemahaman diri juga meliputi harga diri seseorang. Harga diri tumbuh dari dasar pemahaman emosi melalui hubungan sosial dengan orang-orang terdekatnya termasuk orang tua (Hasiana, 2020). Di sisi lain, interaksi sosial merupakan kebutuhan utama setiap manusia (Fitriyah, 2019). Dengan demikian, hal ini sangat penting bagi anak untuk memahami, berpikir, bertindak dan bisa merasakan apa yang sedang terjadi di lingkungannya agar anak mampu mengolah antara emosi 
dan logika dengan tepat di dalam kehidupannya (Bruno \& Joyce, 2014; Bosacki, 2014; Keshky \& Samak, 2017; Hosogi et al, 2012; Azizah \& Hastuti, 2019; Ikiz et al, 2010; Biro et al, 2006; Kazemi et al, 2016; Mayberry, 1990).

Maria Antoinete menjelaskan bahwa orang yang memahami diri adalah mereka yang memiliki tujuan hidup, memiliki arah, rasa memiliki kewajiban dan alasan untuk ada (eksis), identitas diri yang jelas dan kesadaran sosial yang tinggi. Menurut Santrock, Pemahaman diri (selfunderstanding) adalah gambaran kognitif remaja mengenai dirinya, dasar, dan isi dari konsep diri remaja. Pemahaman diri adalah suatu cara untuk memahami, menaksir karakteristik, potensi dan atau masalah (gangguan) yang ada pada individu atau sekelompok individu. Dari uraian diatas, penulis menyimpulkan bahwa pemahaman diri adalah suatu situasi yang dialami individu di mana seseorang mengenal tentang potensinya baik potensi fisik maupun potensi psikisya, sehingga individu memahami arah dan tujuan hidup atau cita-citanya. Potensi fisik yaitu sejumlah kemampuan yang ada pada anggota badan dan panca indra individu, sedangkan potensi psikis individu mencakup minat, abilitas, kepribadian, nilai dan sikap. Pemahaman yang dimaksudkan di sini tidak hanya terbatas pada pengenalan anak atas keunggulannya saja, tetapi juga mencakup pengelan anak atas kekurangan yang ada dalam diri.

Selain pemahaman diri, tanggung jawab adalah usaha yang dilakukan oleh individu untuk menjaga dirinya sendiri maupun menjaga orang lain, sehingga membentuk individu yang dapat menjalankan kewajibannya untuk ikut serta dalam kegiatan yang diselenggarakan di masyarakat. Akar perkembangan tanggung jawab sosial individu terletak pada fungsi empati, regulasi emosi dan identitas diri. Anita Lie \& Sarah Prasasti mengungkapkan bahwa sikap tanggung jawab anak dapat dimulai dari yang sederhana. Mulai dari menjaga barang miliknya sendiri, merapikan kamar tidur dan kemudian merapikan alat-alat permainan yang telah digunakan (Lickona, 2012; Bjerke, 2011; Phajane, 2014; Wray-lake \& Syvertsen, 2011).

Sementara itu Yaumi (2014) tanggung jawab adalah suatu tugas atau kewajiban untuk melakukan atau menyelesaikan tugas dengan penuh kepuasan (yang diberikan oleh seseorang atau atas janji komitmen sendiri) yang harus dipenuhi oleh seseorang dan yang memiliki konsekuen hukuman terhadap kegagalan. Dikutip dari Talking Tree books, tanggung jawab bagi anak adalah sesuatu yang harus mereka lakukan. Tanggung jawab berupa tugas yang harus dilakukan, misalnya tanggung jawab mengerjakan untuk menyikat gigi sebelum tidur, maka hal tersebut wajib mereka lakukan setiap malamnya.

Penelitian ini mengacu pada penelitian terdahulu yang ditulis oleh Erfita, dkk (2018) yang berjudul "Pengaruh Iklim Sekolah dan Konsep Diri Terhadap Pembentukan Sikap Tanggung Jawab". Hasil penelitian tersebut menunjukkan terdapat pengaruh konsep diri terhadap pembentukan sikap tanggung jawab dengan kontribusi 12,2\%. Pentingnya penguatan nilai karakter tanggung jawab didasarkan pada alasan bahwa banyaknya terjadi penyimpangan perilaku pada peserta didik di sekolah seperti membuat keributan di kelas, tidak mengerjakan tugas, tidak memakai atribut lengkap saat upacara, bolos sekolah, berkelahi dengan teman bahkan membantah guru.

Pelanggaran yang dilakukan oleh peserta didik tidak hanya terjadi sekali, tetapi berulang-ulang kali bahkan di sekolah banyak terjadi perilaku bullying yang membuat peserta didik tidak nyaman. Dengan begitu, sekolah diharapkan mampu menciptakan iklim yang kondusif untuk mewujudkan nilai-nilai karakter peserta didik dalam tindakan sehari-hari di sekolah. Berdasarkan uraian tersebut, penelitian ini berkeinginan untuk menganalisis dan mendiskripsikan pengaruh iklim 
sekolah dan konsep diri tehadap pembentukan sikap tanggung jawab peserta didik SMP Islam Terpadu Permata Bunda.

Penelitian Aisyah, dkk (2014) dengan judul "Meningkatkan tanggung jawab belajar melalui layanan penguasaan konten" menunjukkan tanggung jawab belajar siswa dapat ditingkatkan melalui layanan penguasaan konten. Layanan penguasaan konten yaitu, pengenalan dan pengembangan motivasi, sikap, dan kebiasaan belajar yang baik. Dengan pemberian konten sebagai stimulus, siswa dipacu untuk memahami, mempelajari, dan mengembangkan dirinya sesuai dengan isi konten tersebut. Penelitian Rohyati (2015) yang berjudul "Peningkatan Sikap Tanggung Jawab Anak Usia 5-6 Tahun melalui Metode Proyek Di TK Tunas Ibu Kalasan" menunjukkan bahwa sikap tanggung jawab dapat ditingkatkan melalui metode proyek. Hal ini dikarenakan proses pembelajaran metode proyek menekankan pada sikap tanggung jawab yang diberikan kepada anak memberikan kepercayaan kepada anak untuk melakukan proyek secara mandiri dan proyek yang dilakukan menyesuaikan dengan kemampuan anak.

Berdasarkan hasil pengamatan peneliti yang dilakukan pada bulan Januari 2020 di beberapa sekolah pendidikan anak usia dini yang berada di Kecamatan Tenggilis Mejoyo Kota Surabaya, dapat diketahui bahwa pemahaman diri anak masih harus ditingkatkan lagi dalam memahami kemampuan yang ada di dalam dirinya, bahkan masih sangat malu untuk menjelaskan tentang kemampuan dirinya sendiri, ini banyak dialami oleh anak laki-laki dan sebagian anak perempuan. Ketika peneliti berinteraksi dengan anak-anak perempuan, mereka lebih antusias dalam menceritakan tentang dirinya sendiri, contohnya "aku cantik dan aku juga bisa menggambar ikan sendiri tanpa bantuan siapapun”. Sedangkan ketika peneliti berinteraksi dengan anak laki-laki, mereka cenderung berisik sendiri dan melakukan kegiatannya masing-masing, tetapi ada sebagian yang mendengarkan dan bisa mengatakan bahwa teman perempuannya itu cantik. Kemudian ada yang bercerita juga tentang kondisi keluarganya, sehingga membuat dia meraa sedih saat itu. Berbeda halnya dengan kemampuan pemahaman diri, mereka memiliki rasa tanggung jawab yang sangat bagus. Anak mampu mengerjakan dan menyelesaikan tugasnya dengan tuntas dan tepat waktu, bisa merapikan dan meletakkan mainan ke tempatnya masing-masing.

Berdasarkan uraian di atas, maka perlu dilakukan penelitian mengenai pengaruh pemahaman diri terhadap rasa tanggung jawab pada anak usia dini dalam meningkatkan kemampuan dan kreatifitas seorang anak. Hal ini berarti bahwa anak yang memiliki motivasi tinggi akan mendapatkan dorongan yang lebih baik dari lingkungannya, karena pemahaman diri dan rasa tanggung jawab merupakan proses awal dan modal yang harus dimiliki anak dalam menjalani kehidupan di massa mendatang dengan harapan anak menjadi terbiasa dengan sikap tanggung jawab, toleransi dan percaya diri yang akan berkembang secara terus menerus sampai anak menjadi dewasa. Tujuan dari penelitian ini untuk mengetahui hubungan kemampuan memahami diri terhadap rasa tanggung jawab pada anak usia dini di Kecamatan Tengilis Mejoyo Kota Surabaya. Serta ruang lingkup kajian penelitian ini terbatas pada beberapa hal, yaitu diantaranya pemahaman diri berhubungan dengan sikap dan keyakinan tentang diri sendiri, rasa tanggung jawab berhubungan dengan kewajiban dengan menyelesaikan tugas tugasnya. Selain itu,obyek peneliti hanya terbatas pada anak usia 5 - 6 tahun di TK A, TK B dan TK C Surabaya.

\section{Metodologi}

Penelitian ini adalah penelitian deskriptif dengan pendekatan kuantitatif. Populasi dalam penelitian ini adalah seluruh sekolah taman kanak-kanak sekecamatan Tenggilis Mejoyo dengan teknik pengambilan sampel penelitian ini adalah cluster random sampling. Instrumen dalam 
penelitian ini menggunakan skala likert untuk mengukur pendapat seseorang tentang pemahaman diri dan tanggung jawab anak usia dini. Sebagai acuan dalam pengambilan data, penelitian ini menggunakan dua instrument, diantaranya instrumen yang pertama Self-Description Questionnair (SDQ) untuk mengukur pemahaman diri yang dibuat oleh Marsh, et al (2005). Adapun instrumen yang kedua adalah Mental Representation of Caregiving (MRC) yang dibuat oleh Reizer \& Mikulincer (2007) bersumber dari Helping Attitudes Scale (HASE).

Variabel Pemahaman Diri (Y) merupakan suatu bentuk upaya pencitraan diri seseorang tentang bagaimana individu tersebut memahami akan kekurangan dan kelebihannya. Maka, individu tersebut akan membentuk rasa percaya diri yang timbul dari pemahaman dirinya, karena orang dengan percaya diri tinggi juga sangat sadar diri. Variabel Tanggung Jawab (X1) Tanggung jawab adalah kesadaran diri manusia terhadap semua tingkah laku dan perbuatan yang disengaja ataupun tidak disengaja. Tanggung jawab juga harus berasal dari dalam hati dan kemauan diri sendiri atas kewajiban yang harus di tanggung jawabkan.

Penelitian ini dilakukan dengan menggunakan instrumen pemahaman diri dan tanggung jawab yang diisi oleh seluruh responden yang telah ditetapkan, yaitu seluruh guru TK yang mengajar di TK A, TK B dan TK C. Sebelum penyebaran instrumen dilakukan kepada responden di tempat penelitian, terlebih dahulu peneliti melakukan uji coba instrumen di TK D. Diketahui hasil uji validitas instrumen pemahaman diri, yaitu butir valid 13 dan butir invalid 0 dengan total keseluruhan 13 butir pertanyaan dan nilai cronbach's alpha reliabilitas mencapai 0,715, sedangkan hasil uji validitas instrumen rasa tanggung jawab yaitu jumlah butir valid 17 dan jumlah butir invalid 3 dengan total keseluruhan 20 pertanyaan dan nilai cronbach's alpha reliabilitas mencapai 0,740 .

Teknik analisis data yang digunakan dalam penelitian ini yaitu rumus regresi linear sederhana. Teknik analisis data yang digunakan yaitu pemeriksaan terhadap instrumen yang diberikan dan diisi oleh responden. Menganalisis angket sesuai dengan indikator yang telah diberikan, jawaban yang terdapat pada instrumen dan berdasarkan skor sesuai dengan skala likert. Setelah uji validasi selesai dan instumen telah valid, maka angket siap disebar kepada responden serta data dikumpulkan, kemudian diolah dengan menghitungnya. Data direkapitualsi untuk mengetahui frekuensi serta untuk menentukan mean atau rata-rata, serta rata-rata skor. Data tersebut telah dilakukan uji asumsi klasik (uji homogenitas, uji normalitas, dan uji heterokedastisitas) dan telah dinyatakan memenuhi asumsi, sehingga dapat dilakukan analisis dengan regresi linear sederhana.

\section{Hasil dan Pembahasan}

Statistik deskriptif dalam penelitian ini merujuk pada nilai rata-rata (mean) dan simpanan baku (standard deviation), nilai minimum dan maksimum serta dari seluruh variabel dalam penelitian ini yaitu pemahaman diri (Y) dan rasa tanggung jawab (X1) pada anak sebagaimana ditunjukkan pada tabel dibawah ini:

Tabel 1. Analisis Statistik Deskripstif Masing-masing Variabel

\begin{tabular}{|l|c|c|c|c|c|}
\hline & $\mathrm{N}$ & Minimum & Maximum & Mean & Std. Deviation \\
\hline Tanggung Jawab (X1) & 134 & 33 & 77 & 60.73 & 8.628 \\
\hline Pemahaman Diri (Y) & 134 & 36 & 64 & 52.39 & 5.931 \\
\hline Valid N (listwise) & 134 & & & & \\
\hline
\end{tabular}


Pada tabel $1 \mathrm{di}$ atas, variabel tanggung jawab mempunyai nilai $\mathrm{M}=60.73, \mathrm{SD}=8.628$, hal ini berarti bahwa nilai mean lebih besar dari pada standar deviasi, sehingga mengindikasikan bahwa hasil yang cukup baik. Hal tersebut dikarenakan standar deviasi adalah pencerminan penyimpangan yang sangat tinggi, sehingga penyebaran data menunjukkan hasil yang normal dan tidak menyebabkan bias. Nilai minimalnya sebesar 33 dan nilai maksimumnya sebesar 77. Sedangkan variabel pemahaman diri mempunyai nilai $\mathrm{M}=52.39, \mathrm{SD}=5.931$. Hal ini mengindikasikan bahwa hasil yang cukup baik, nilai minimalnya sebesar 36 dan nilai maksimumnya sebesar 64 .

Tabel 2. Hasil Uji Regresi Y - X1

\begin{tabular}{|l|r|r|r|r|r|}
\hline \multirow{2}{*}{ Model } & \multicolumn{2}{|c|}{ Unstandardized Coefficients } & \multicolumn{1}{c|}{$\begin{array}{c}\text { Standardized } \\
\text { Coefficients }\end{array}$} & \multirow{2}{*}{ t } & \multirow{2}{*}{ sig } \\
\cline { 2 - 5 } & \multicolumn{1}{|c|}{ B } & Std.Error & \multicolumn{1}{c|}{ Beta } & & .000 \\
\hline 1.(Constant) & 36.721 & 3.401 & & 10.796 & .375 \\
Tanggung Jawab (X1) & .258 & .055 & 4.652 & .000 \\
\hline
\end{tabular}

a. Dependent Variable; Pemahaman Diri (Y)

Berdasarkan di atas diketahui nilai signifikansi sebesar 0,000 lebih kecil dari < probabilitas 0,05, sehingga dapat disimpulkan bahwa $\mathrm{HO}$ ditolak dan $\mathrm{H} 1$ diterima, yang berarti bahwa ada hubungan antara pemahaman diri terhadap rasa tanggung jawab pada anak usia dini. Koefisien determinasi $r$ square sebesar 0,141 yang berarti 1,41\% sumbangan pengaruh tanggung jawab (X1) terahadap pemahaman diri $(\mathrm{Y})$. Berikut merupakan garis regresi $\mathrm{Y}=36.721+0,258 \mathrm{X}$. Nilai konstanta adalah 36,721 hal ini berarti bermakna positif dan dapat diartikan setiap peningkatan tanggung jawab sebesar 1, maka pemahaman diri juga akan meningkat sebesar 0,258. Berdasarkan interpretasi koefisien korelasi ( $\mathrm{r}$ hitung), maka nilai $\mathrm{r}$ hitung sebesar 0,375 termasuk memiliki tingkat hubungan yang cukup antara kedua variabel.

Penelitian ini sama dengan hasil penelitian Erfita, dkk (2018) yang menunjukkan bahwa terdapat pengaruh konsep diri terhadap pembentukan sikap tanggung jawab dengan kontribusi $12,2 \%$, jadi semakin baik kemampuan memahami diri, maka akan semakin tinggi tingkat rasa tanggung jawabnya. Penelitian ini sejalan dengan penelitian Saputra (2019) yang menyebutkan bahwa tanggung jawab berpengaruh terhadap rasa percaya diri siswa kelas IV SD se-gugus 1 Panjatan Kabupaten Kulonprogo sebesar 0,3\%. Semakin baik rasa tanggung jawabnya, maka akan semakin tinggi juga tingkat rasa percaya dirinya. Penelitian Nur'aini (2018) dengan judul "Hubungan antara Kepercayaan Diri dengan Kemandirian Siswa MTs Ma'arif Durensewu Pandaan" yang menunjukkan bahwa terdapat hubungan yang signifikan antara kepercayaan diri dengan kemandirian. Artinya, semakin tinggi kepercayaan diri siswa, maka tingkat kemandiriannya juga tinggi. Jadi, dapat disimpulkan bahwa rasa tanggung jawab mempunyai hubungan positif terhadap pemahaman diri pada anak usia dini di Kecamatan Tenggilis Mejoyo. Walaupun memiliki tingkat hubungan yang cukup antar kedua variabel. Anak yang mempunyai konsep diri positif, maka akan memiliki sikap tanggung jawab akan tugas dan kewajibannya. Konsep diri yang positif perlu ditingkatkan agar anak memiliki sikap yang positif juga dalam dirinya, diantaranya sikap tanggung jawab. Ada beberapa cara yang dapat dilakukan untuk menumbuhkan konsep diri yang positif agar tumbuh sikap yang positif antara lain: Membuat anak merasa mendapat dukungan dari guru, membuat anak merasa bertanggung jawab, membuat anak merasa mampu, mendidik anak untuk mencapai tujuan yang realistis, membantu anak menilai diri mereka secara realistis, mendorong anak agar bangga dengan dirinya secara realistis. 
Berdasarkan tabel 4 di atas dapat diketahui juga nilai signifikansi variabel tanggung jawab (X1) adalah sebesar 0,000, karena nilai Signifikansinya 0,000 < probabilitas 0,05, sehingga dapat disimpulkan bahwa H1 atau hipotesis diterima. Artinya ada hubungan tanggung jawab (X1) terhadap pemahaman diri (Y). Sedangkan untuk perbandingan nilai $t$ hitung dengan $t$ tabel dapat diketahui nilai t hitung variabel tanggung jawab adalah sebesar 4,652 >t tabel 1,960, maka dapat disimpulkan bahwa ada hubungan tanggung jawab (X1) terhadap pemahaman diri (Y).

\section{Kesimpulan}

Berdasarkan uraian hasil dan pembahasan di atas, maka dapat disimpulan bahwa terdapat hubungan positif yang signifikan antara pemahaman diri dan rasa tanggung jawab anak usia dini. Artinya, indikator-indikator pemahaman diri pada anak usia dini berkontribusi terhadap rasa tanggung jawab mereka. Rekomendasi untuk penelitian selanjutnya adalah perlu adanya rumusan strategi pembelajaran untuk anak usia dini yang dapat meningkatkan pemahaman diri dan rasa tanggung jawab.

\section{Daftar Pustaka}

Adywibowo, I. P. (2010). Memperkuat Kepercayaan Diri Anak Melalui Percakapan Referensial. Jurnal Pendidikan Penabur, 9(15), 37-49.

Aisyah, A., Nusantoro, E., \& Kurniawan, K. (2014). Meningkatkan Tanggung Jawab Belajar Melalui Layanan Penguasaan Konten. Indonesian Journal of Guidance and Counseling, $3(3), 44-50$.

Azizah, S. A. N., \& Hastuti, D. (2019). The Influence of Maternal Acceptance-Rejection and Adolescents Self Esteem to Bullying Behavior Junior High School Students. Journal of Family Sciences, 4(1), 12-25.

Biro, F. M., Striegel-Moore, R. H., Franko, D. L., Padgett, J., \& Bean, J. A. (2006). Self-Esteem in Adolescent Females. Journal of Adolescent Health, 39, 501-507. https://doi.org/10.1016/j.jadohealth.2006.03.010

Bjerke, H. (2011). Children as ' differently equal' responsible beings : Norwegian children ' s views of responsibility. SAGE Journals, 18(1) https://doi.org/10.1177/0907568210371987

Bosacki, S. L. (2014). A Longitudinal Study of Children' s Theory of Mind, Self-Concept, and Gender-Role Orientation. International Electronic Journal of Elementary Education, 6(2), 213-228.

Bruno, U. D. O., \& Joyce, N. (2014). The Role of the Teacher in Improving Students Self Esteem. International Journal of Academic Research in Progressive Education and Development, 3(1), 47-53. https://doi.org/10.6007/JJARPED/v3-i1/615.

Cahyaningrum, E. S., Sudaryanti, S., \& Purwanto, N. A. (2017). Pengembangan Nilai-Nilai Karakter Anak Usia Dini Melalui Pembiasaan Dan Keteladanan. Jurnal Pendidikan Anak, 6(2), 203-213. https://doi.org/10.21831/jpa.v6i2.17707.

Erfita, F., Suntoro, I., \& Yanzi, H. (2018). Pengaruh Iklim Sekolah dan Konsep Diri Terhadap Pembentukan Sikap Tanggung Jawab. Jurnal Kultur Demkrasi, 5(9), 1-13

Fitriyah, F. K. (2019). Pengaruh Permainan Tradisional Gobak Sodor Dalam Bimbingan Kelompok Terhadap Peningkatan Interaksi Sosial Anak Autis. Education and Human Development Journal, 4(2), 13-20. https://doi.org/10.33086/ehdj.v4i2.1293.

Hasiana, I. (2020). Peran Keluarga dalam Pengendalian Perilaku Emosional pada Anak Usia 5-6 Tahun. Child Education Journal, 2(1), 24-33. https://doi.org/10.33086/cej.v2i1.1538.

Hastuti, D. (2016). Strategi Pengembangan Harga Diri Anak Usia Dini. Jurnal Pendidikan Sekolah Dasar, 2(2), 38-50

Hosogi, M., Okada, A., Fujii, C., Noguchi, K., \& Watanabe, K. (2012). Importance and Usefulness of Evaluating Self- esteem in children. BioPsychoSocial Medicine, 6(9), 1-6.

Child Education Journal. Volume 2, No. 2 December 2020, 98-105 
Ikiz, F. E., \& Cakar, F. S. (2010). Perceived social support and self-esteem in adolescence. Procedia-Sosial and Behavioral Sciences, 5, 2338-2342. https://doi.org/10.1016/j.sbspro.2010.07.460

Kazemi, Y., Nikmanesh, Z., \& Khosravi, M. (2016). The Relationship Between Quality of Life and Self-esteem and Attribution Styles in Primary School Students. Iranian Journal of Psychiatry and Behavioral Sciences, 11(4), 1-6 https://doi.org/10.5812/ijpbs.5850.

Keshky, M. E. S. E., \& Samak, Y. A. A. (2017). The Development of Self Esteem in Children: Systematic Review and Meta-Analysis. International Journal of Psychology \& Behavior Analysis, 3(128), 1-8

Lickona, T. (2012). Educating for Character: How Our School Can Teach Respect and Responsibility (Mendidik untuk Membentuk Karakter). Jakarta: Bumi Aksara.

Mann, M. M., Hosman, C. M. H., Schaalma, H. P., \& Vries, N. K. D. (2004). Self-esteem in a Broad-spectrum Approach for Mental Health Promotion. Health Education Research, 19(4), 357-372. https://doi.org/10.1093/her/cyg041

Marsh, H. W., Ellis, L. A., Parada, R. H., Richard, G., \& Heubeck, B. G. (2005). A Short Version of The Self Description Questionnair II: Operationalizing Criteria for Short-Form Evaluation With New Applications of Confirmatory Factor Analyses. Psychological Assessment, 17(1), 81-102

Mayberry, W. (1990). Self-Esteem in Children: Considerations for Measurement and Intervention. The American Journal of Occupational Therapy, 44, 729-734.

Mukhtar., Yusuf, S., \& Budiamin, A. (2016). Program Layanan Bimbingan Klasikal untuk Meningkatkan Self-Cotrol Siswa. PSIKOPEDAGOGIA: Jurnal Bimbingan dan Konseling, $5(1), 1-16$

Nur'aini, S. (2018). Hubungan Antara Kepercayaan Diri Dengan Kemandirian Siswa MTs Ma 'arif Durensewu Pandaan. Skripsi. Malang: Universitas Negeri Malang

Phajane, M. H. (2014). Exploring the Roles and Responsibilities of Early Childhood Teachers. Mediterranean Journal of Social Sciences, 5(10), 420-424.

Praptiani, S.(2013). Pengaruh Kontrol Diri Terhadap Agresivitas Remaja Dalam Menghadapi Konflik Sebaya dan Pemaknaan Gender. Jurnal Sains dan Praktik Psikologi, 1 (1), 01-13.

Reizer, A., \& Mikulincer, M. (2007). Assessing Individual Differences in Working Models of Caregiving: The Construction and Validation of The Mental Representation of Caregiving Scale. Journal of Individual Differences, 28(4), 227-239

Rohyati. (2015). Peningkatan Sikap Tanggung Jawab Anak Usia 5-6 Tahun Melalui Metode Proyek Di Tk Tunas Ibu Kalasan. Skripsi. Yogyakarta: UNY

Saputra, Y. B. (2019). Pengaruh Tangggung Jawab Terhadap Rasa Percaya Diri Siswa Kelas IV SD Se-Gugus I Kecamatan Panjatan Kabupaten Kulon Progo. Jurnal Pendidikan Guru Sekolah Dasar, 8(5), 431-438

Syam, A., \& Amri, A. (2017). Pengaruh Kepercayaan Diri (Self Confidence) Berbasis Kaderisasi Imm Terhadap Prestasi Belajar Mahasiswa (Studi Kasus Di Program Studi Pendidikan Biologi Fakultas Keguruan Dan Ilmu Pendidikan Universitas Muhammadiyah Parepare). Jurnal BIOTEK, 5(1), 87-102.

Thahir, A., \& Firdaus. (2017). Peningkatkan Konsep Diri Positif Peserta Didik di SMP Menggunakan Konseling Individu Rational Emotive Behavior Therapy (REBT). Konseli: Jurnal Bimbingan dan Konseling, 4(2), 47-64.

Wray-lake, L., \& Syvertsen, A. K. (2011). The Developmental Roots of Social Responsibility in Childhood and Adolescence. PubMed, 134, 11-25

Yaumi, M. (2014). Pendidikan karakter landasan, pilar dan implementasi. Jakarta: Prenadamedia Group. 